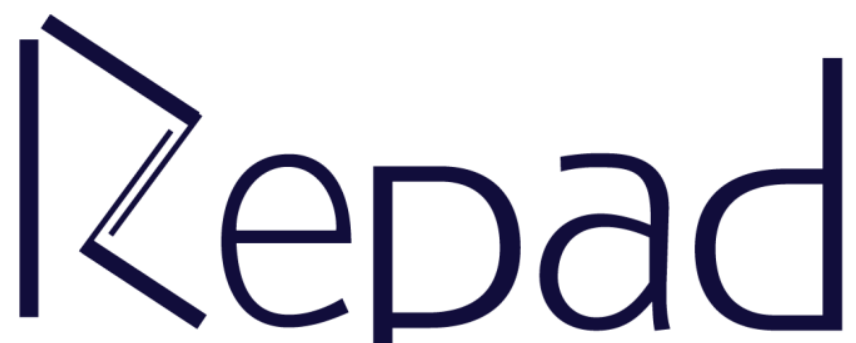

vol. 3, n. 3, Setembro-Dezembro/2019

Revista Estudos e

Pesquisas em Administração 


\title{
A EFETIVIDADE DO PROJETO DE LEI DO SENADO N 116/2017 COMO INSTRUMENTO PARA A EFICIÊNCIA NO SERVIÇO PÚBLICO: Um estudo à luz da avaliação de desempenho dos servidores da UFRPE
}

\author{
Evelyne Alvares Ribeiro \\ Universidade Federal de Pernambuco, Recife, Pernambuco, Brasil \\ evelynear@hotmail.com \\ https://orcid.org/0000-0002-6726-7418
}

\section{Resumo}

Este artigo teve como objetivo analisar a efetividade do Projeto de Lei do Senado (116/2017), utilizando como instrumento de mensuração da eficiência no serviço público, a comparabilidade da atual avaliação de desempenho para progressão das Instituições Federais de Ensino Superior. Para atingir esse objetivo, foi realizada uma pesquisa de campo na Universidade Federal Rural de Pernambuco, por meio de questionários on-line (GoogleDocs) com gestores, bem como pesquisadas na literatura, amostra de pesquisa referente à avaliação de desempenho em instituições educacionais a serem comparadas . Dessa forma, evidenciou-se que, apesar da criação de instrumentos capazes de auxiliar na busca pela eficiência, ainda existe forte presença de clientelismo e corporativismo no serviço público, resultando na falta de efetividade das ferramentas atuais que visam medir a eficiência do servidor, levando os gerentes a inferir que o mesmo acontecerá com a avaliação proposta no novo projeto de lei do Senado. Conclui-se, portanto, que novos mecanismos organizacionais são necessários para obter eficiência no serviço público, pois algumas práticas ainda estão enraizadas na gestão pública, não permitindo que a avaliação de desempenho possa modificar a cultura organizacional atual.

Palavras-chave: Avaliação de desempenho; Eficiência; Projeto de Lei do Senado $\mathrm{n}^{\circ}$ $116 / 2017$.

\section{THE EFFECTIVENESS OF SENATE DRAFT LAW 116/2017 AS AN INSTRUMENT FOR PUBLIC SERVICE EFFICIENCY: A study in light of the performance appraisal of the Federal Rural University of Pernambuco}

\begin{abstract}
This paper aimed to analyze the effectiveness of the Senate Draft Law (116/2017), using as an instrument to measure efficiency in the public service, the comparability of the current performance evaluation for progression of Federal Institutions of Higher Education. To achieve this goal, a field research was conducted at the Federal Rural University of Pernambuco through online questionnaires (GoogleDocs) with managers, as well as searched in the literature, sample of research regarding the performance evaluation in educational institutions to be compared. Thus, it was evidenced that, despite the creation of instruments capable of assisting in the search for efficiency, there is still a strong presence of clientelism and corporatism in the public service, resulting in the lack of effectiveness of current tools aimed at measuring server efficiency, leading managers to infer that the same will happen with the assessment proposed in the new Senate Draft Law. It is concluded, therefore, that new organizational mechanisms are needed to achieve efficiency in the public service, as some practices are still rooted in public management, not allowing performance evaluation to be able to modify the current organizational culture.
\end{abstract}

Keywords: Performance Evaluation; Efficiency; Senate Draft Law 116/2017. 
Submetido: 25/07/2019

Aceito: 07/09/2019

Publicado: 31/12/2019

\section{INTRODUÇÃO}

A necessidade de um serviço público de qualidade se torna cada vez mais manifesta. As pessoas estão cada dia mais, conhecedoras de seus direitos e insatisfeitas com os serviços prestados nos mais diversos setores de atuação do Governo. Pagam-se altos impostos e se espera um retorno por meio da excelência dos serviços públicos, mas a qualidade desse retorno ainda é muito questionada.

Em uma pesquisa realizada no ano de 2016, pela Confederação Nacional da Indústria (CNI), foi avaliada a opinião dos cidadãos sobre a qualidade de treze serviços prestados por órgãos públicos, sendo eles: Fornecimento de energia elétrica; Correios; Fornecimento de água; Iluminação pública; Educação superior; Limpeza urbana; Educação fundamental e ensino médio; Transporte público; Rodovias/estradas; Conservação de ruas e avenidas; Atendimento à população nas repartições públicas; Segurança pública e Postos de saúde e hospitais.

O resultado foi apresentado utilizando um "índice de difusão" que variava entre zero e cem. Valores acima de 50 pontos indicava que a parcela da população que considerava o serviço de alta ou muito alta qualidade era superior à parcela que considerava o serviço de baixa ou muito baixa qualidade, enquanto, valores abaixo de 50 pontos indicava maior avaliação negativa do serviço (RETRATOS DA SOCIEDADE BRASILEIRA 33, 2016). De acordo com a pesquisa, nenhum serviço obteve índice superior a 50, ou seja, nenhum serviço foi considerado de alta qualidade. Como se pode observar no trecho transcrito abaixo:

Os serviços de saúde e segurança são os que apresentam índices mais baixos: os postos de saúde e hospitais apresentam 20 pontos e a segurança pública, 22 pontos. Nenhum serviço público apresenta índice superior a 50, limite a partir do qual a avaliação da qualidade do serviço é considerada positiva. Os três serviços públicos melhor avaliados são fornecimento de energia elétrica (48), Correios (46) e fornecimento de água (42). (RETRATOS DA SOCIEDADE BRASILEIRA 33, 2016, p. 2)

Logo, é de extrema relevância que a Administração Pública seja capaz de modificar suas atividades para proporcionar a tão esperada melhoria dos serviços. Melhoria essa que já é pauta de discussão há anos, e que já resultou na inclusão do princípio da eficiência na Constituição Federal (CF), conforme Emenda Constitucional $\mathrm{n}^{\circ} 19$, de 04 de junho de 1998 (EMC n ${ }^{\circ}$ 19/98), que destaca como dever do servidor público a maximização dos resultados mediante a eficiência nas atividades, objetivando assim, alcançar o interesse coletivo de forma satisfatória.

O princípio da eficiência é entendido por diversos estudiosos como a imposição de uma política administrativa que volta suas práticas para a administração por resultados, com o intuito de alcançar a plena eficiência do gasto público e de gerar serviços de qualidade para a sociedade. Neste sentido, Meirelles (2003) discorre:

O princípio da eficiência exige que a atividade administrativa seja exercida com presteza, perfeição e rendimento funcional. É o mais 
moderno princípio da função administrativa, que já não se contenta em ser desempenhada apenas com legalidade, exigindo resultados positivos, para o serviço público e satisfatório atendimento das necessidades da comunidade e de seus membros (MEIRELLES, 2003, p. 94).

Porém, vinte e um anos após a constitucionalização desse princípio, alguns órgãos públicos permanecem com a imagem de prestarem serviços que não satisfazem as necessidades da população, sendo imputada, por muitos, a culpa dessa ineficiência aos servidores públicos, que terminam sendo estereotipados, perante a sociedade, como incompetentes, ineficientes ou mesmo preguiçosos. Um dos motivos apontados como causa para a possível insuficiência de desempenho desses servidores é a estabilidade que o serviço público proporciona, como pontuado por Bergue (2010, p. 23) "não são raras as vozes que apontam essa figura jurídica como fator de acomodação do agente público". Os servidores públicos só podem perder o cargo nos seguintes casos:

Art. 41. São estáveis após três anos de efetivo exercício os servidores nomeados para cargo de provimento efetivo em virtude de concurso público.

$\S 1^{\circ} \mathrm{O}$ servidor público estável só perderá o cargo:

I - em virtude de sentença judicial transitada em julgado;

II - mediante processo administrativo em que lhe seja assegurada ampla defesa;

III - mediante procedimento de avaliação periódica de desempenho, na forma de lei complementar, assegurada ampla defesa. (CF/98)

Atentando para o inciso III, pode-se observar que o servidor estável pode perder o cargo mediante procedimento de avaliação periódica de desempenho, dependendo de lei complementar específica. Porém, esta lei ainda não foi sancionada, com isso, na prática, o servidor estável não precisa realmente ser eficiente para continuar exercendo suas atribuições no órgão que está lotado.

Baseada na necessidade de regulamentar esse inciso, para atingir a eficiência do serviço público e fazer com que os servidores sejam de certa forma, "obrigados" a seguir um padrão de comportamento, a senadora Maria do Carmo Alves (DEM-SE) propôs um Projeto de Lei do Senado, conhecido por PLS no 116/2017, que dispõe sobre a perda do cargo público por insuficiência de desempenho do servidor público estável. E encontrase atualmente em tramitação no Senado Federal (encaminhado ao Plenário na data de 10/07/19), tendo já sido aprovado com algumas modificações pela Comissão de Constituição, Justiça e Cidadania e pela Comissão de Assuntos Sociais, conforme consulta à atividade legislativa do Senado ${ }^{1}$.

O projeto visa transformar a avaliação de desempenho em um instrumento para concretização do princípio da eficiência no serviço público. Traz como justificativa a necessidade da melhoria contínua do serviço prestado e consequentemente a punição dos servidores que não conseguem acompanhar as mudanças necessárias para atingir esse objetivo, pautado na ideia de que estes servidores ineficientes, além de prejudicarem o serviço, prejudicam a imagem de todos os servidores públicos (BRASIL, 2017).

Contudo, caso esta Lei seja sancionada, ainda existirá dúvidas sobre a incontestabilidade da mesma no que concerne à busca da eficiência, considerando tanto

\footnotetext{
${ }^{1}$ Disponível em: https://www25.senado.leg.br/web/atividade/materias/-/materia/128876?o=c.
} 
o conteúdo da avaliação, se analisa a produtividade e qualidade/excelência do atendimento e serviços prestados nas instituições públicas, quanto a possibilidade de vícios na execução da avaliação, visto que há uma inegável falta de profissionalismo e impessoalidade presentes nas ações de alguns servidores, derivada das históricas práticas clientelistas e corporativistas nos órgãos públicos, como também devido à influência de interesses políticos e pessoais. E foi sob esta perspectiva que surgiu o problema que norteou essa pesquisa: A avaliação de desempenho proposta pelo Projeto de Lei do Senado $n^{o}$ 116/2017 pode ser considerada um instrumento efetivo para mensurar a eficiência do servidor?

Com o intuito de responder a esta pergunta foi analisada a percepção dos gestores da Universidade Federal Rural de Pernambuco (UFRPE) em relação a efetividade da avaliação de desempenho já existente na Instituição Federal de Ensino Superior (IFES), que visa a progressão por mérito profissional dos servidores, decorrente da Lei $\mathrm{n}^{\circ}$ 11.091/2005, que "dispõe sobre a estruturação do Plano de Carreira dos Cargos TécnicoAdministrativos em Educação, no âmbito das Instituições Federais de Ensino vinculadas ao Ministério da Educação, e dá outras providências". Conforme previsto no artigo 10 da referida Lei:

Art. 10. O desenvolvimento do servidor na carreira dar-se-á, exclusivamente, pela mudança de nível de capacitação e de padrão de vencimento mediante, respectivamente, Progressão por Capacitação Profissional ou Progressão por Mérito Profissional. [...]

$\S 2$ o Progressão por Mérito Profissional é a mudança para o padrão de vencimento imediatamente subsequente, a cada 2 (dois) anos de efetivo exercício, desde que o servidor apresente resultado fixado em programa de avaliação de desempenho, observado o respectivo nível de capacitação.

Desta lei, decorre a avaliação de desempenho para progressão que é aplicada nas instituições de ensino de diferentes maneiras, na UFRPE é realizada utilizando-se formulários que apresentam indicadores, que devem ser analisados pelos próprios servidores (Formulário de Auto avaliação), pelos colegas de trabalho (Formulário de Avaliação de Equipe de Trabalho) e pelos chefes imediatos (Formulário de Avaliação da Chefia Imediata). Esta avaliação, que tem periodicidade de 18 meses, possui indicadores de desempenho semelhantes aos propostos no PLS n ${ }^{\circ} 116 / 2017$, como pode-se ver na seção 3 .

O objetivo desta pesquisa foi identificar a percepção dos gestores da UFRPE sobre a efetividade da avaliação de desempenho proposta no Projeto de Lei do Senado de $\mathrm{n}^{\circ}$ 116/2017 como instrumento para medir a eficiência no serviço público, utilizando como base de comparabilidade a atual avaliação de desempenho dos servidores para progressão por mérito, que tem em sua essência a maior parte dos critérios levantados pelo projeto para o alcance da eficiência do servidor, como apresentado na seção 3 deste artigo.

Logo, esta pesquisa se justifica pela necessidade de analisar se o método proposto será capaz de servir como elemento para a concretização do princípio da eficiência, com o intuito de alcançar um serviço público de qualidade, com o comprometimento de todos os agentes públicos, em cumprimento ao determinado pela EC $\mathrm{n}^{\circ}$ 19/98. Em outras palavras, o estudo busca avaliar a efetividade da avaliação proposta no PLS como um instrumento para atingir a eficiência no serviço público. 


\section{Avaliação de desempenho, breve histórico, importância e entraves}

A prática da avaliação no seu sentido genérico é algo intrínseco ao ser humano, como apontado por Lucena (1995, p. 35), "é o exercício da análise e do julgamento sobre a natureza, sobre o mundo que nos cerca e sobre as ações humanas. É a base para apreciação de um fato, de uma ideia, de um objetivo ou de um resultado e, também a base para a tomada de decisão sobre qualquer situação que envolve uma escolha".

Logo, as organizações, por serem compostas por pessoas, não são dissociadas dessa prática. Historicamente, segundo Lucena (1995), o processo de avaliação de desempenho no trabalho, data desde a época dos jesuítas, que ao partirem para suas missões em países colonizados se submetiam a uma rigorosa avaliação adotada pela Igreja Católica. Já em relação a avaliação de desempenho dos recursos humanos nas organizações, a autora aponta que os precursores foram as instituições Militares e o Estado (Administração Pública), que por sua vez absorveram o modelo militar. Dessa forma, as influências desses modelos na estrutura administrativa foram evidentes até aproximadamente a Segunda Guerra, nas quais prevaleciam a hierarquização e centralização (LUCENA, 1995).

Com o passar dos anos, as mudanças dentro e fora das instituições transformaram o cenário das organizações e do mercado como um todo, a Revolução Industrial, a globalização, o advento da tecnologia, a competitividade, foram alguns dos responsáveis pela modificação da demanda e consequentemente das estruturas e culturas das instituições, tanto privadas como públicas. Vários autores estudaram a importância da relação homem/trabalho para as organizações durante esse tempo, como Taylor, com uma abordagem mais mecanicista, Mayo, McGregor, Herzberg, dentre outros, com uma perspectiva mais psicológica. Todos contribuíram de alguma forma para o estudo do comportamento humano e, por conseguinte da avaliação de desempenho no trabalho.

A avaliação de desempenho passou a ser um elemento importante para a gestão de pessoas nas organizações. Porém, é necessário que seja utilizada de maneira correta para se tornar uma ferramenta propulsora no alcance das metas da instituição, como também na análise de clima organizacional, por exemplo. Como pontuado por Martins (2018):

A popularização da avaliação como ferramenta gerencial, contudo, veio
ocorrer após a Segunda Guerra Mundial, sendo a avaliação hoje uma das
mais relevantes áreas na gestão de pessoas de uma organização, seja ela
pública ou privada, com as finalidades de gerar motivação e
autoconhecimento entre a equipe de trabalho e subsidiar planos de
capacitação e desenvolvimento profissional, desde que não se resuma ao
preenchimento mecânico de formulários (MARTINS, 2018, p. 15).

Nesse contexto, ela desempenha um papel significativo para alcançar a eficiência almejada no serviço público, pois pode auxiliar na análise do comportamento dos servidores públicos, trazendo informações úteis para a tomada de decisão, resultando numa melhor gestão do capital humano em prol da sociedade, como destacado por Martins (2018):

Em virtude das transformações pelas quais passou o mundo nas últimas décadas, a sociedade espera, por parte do serviço público, excelência na gestão e no atendimento, de forma que se perceba a alocação de 
recursos da maneira mais eficiente possível. Nesse contexto a avaliação de desempenho cumpre importante papel estratégico, pois é uma das ferramentas que, se bem aplicada e assimilada por todos, pode gerar informações sobre as competências individuais de cada servidor, podendo ser utilizada como auxílio na tomada de decisões no momento de distribuição dos servidores, das necessidades de capacitação e aperfeiçoamento e mesmo quais os aspectos em que o servidor deve buscar melhorar (MARTINS, 2018, p. 17).

Na administração pública a avaliação de desempenho como instrumento capaz de modificar o comportamento organizacional começou a ganhar notoriedade no governo de Fernando Henrique Cardoso, com a reforma gerencial do Estado (LUCENA, 1995), praticamente na mesma época da constitucionalização do princípio da eficiência. A relação entre avaliação de desempenho e eficiência é destacada por Bergamini e Beraldo (2010):

\begin{abstract}
Avaliar o desempenho das pessoas no trabalho implica, consequentemente, conhecer a dinâmica comportamental própria de cada um, o trabalho a ser realizado e o ambiente organizacional em que essas ações se passam. A eficiência de uma pessoa no desempenho de uma tarefa depende diretamente de uma relação positiva entre essas três variáveis: a maneira de ser ou estilo do indivíduo, a atividade e o ambiente. Quanto maior o ajustamento entre estilo x tarefa/atividade e ambiente, mais eficiente será o resultado do desempenho (BERGAMINI; BERALDO, 2010, p. 32).
\end{abstract}

$\mathrm{Na}$ tentativa de implementar uma gestão mais voltada para resultados foi aprovado, em 2005, o Plano de Cargos e Carreiras dos Técnicos Administrativos em Educação (PCCTAE), Lei 11.091, que trouxe um modelo de avaliação de desempenho para progressão funcional por mérito para as Instituições Federais de Ensino Superior (IFES). E é sob a ótica desse modelo de avaliação que o estudo será pautado quanto a sua efetividade para auxiliar em uma mudança comportamental em busca da eficiência.

Vale destacar que mesmo que a avaliação tenha capacidade de ser um elemento transformador nas instituições públicas, a avaliação de desempenho nas IFES aparenta desempenhar um papel secundário, meramente para progressão salarial, como pode-se observar em alguns estudos realizados em diferentes instituições de ensino, como, por exemplo, na pesquisa de Martins (2018) que concluiu mediante um estudo no Instituto Federal de Educação, Ciência e Tecnologia do Ceará (IFCE) que o objetivo maior da avaliação de desempenho é a progressão; semelhante à realizada por Azevedo (2015) que identificou na perspectiva dos técnicos administrativos da Universidade Federal de Pernambuco (UFPE) que a avaliação de desempenho é um instrumento "superficial e formal para progressão na carreira"; enquanto Costa (2018), em seu estudo no Instituto Federal do Espírito Santo (Campus Alegre), chegou à conclusão que a avaliação de desempenho pouco contribui com a atividade de gestores e servidores do IFES-Alegre. Sendo imprescindível para o sucesso da avaliação de desempenho como instrumento de gestão, que ela seja reformulada, calcada no princípio da democracia, onde servidores e chefias estejam numa posição isonômica.

Pode-se relacionar essa aparente falta de efetividade do instrumento a algumas heranças comportamentais enraizadas na cultura de algumas instituições públicas, como é o caso do clientelismo e corporativismo. O clientelismo pode ser considerado como uma forma institucionalizada historicamente dos entes públicos se relacionar dentro da 
Administração Pública. Acontece quando as relações profissionais são substituídas por relações pessoais e um dos envolvidos vira o "cliente" e o outro o "patrão", devido a isso é conhecido também por patrimonialismo, sobressaindo assim os interesses privados em relação aos interesses públicos. Segundo Nunes (2003), esse termo se originou das relações rurais, como destaca:

A noção de clientelismo foi originalmente associada aos estudos de sociedades rurais. Neste contexto, o clientelismo significa um tipo de relação social marcada por contato pessoal entre patrons e camponeses. Os camponeses, isto é, os clientes, encontram-se em posição de subordinação, dado que não possuem a terra. Os grupos camponeses que serviram de base para o desenvolvimento da noção de clientelismo estavam sempre a um passo da penúria. A desigualdade desempenha um papel-chave na sobrevivência tanto de patrons quanto de clientes e gera uma série de laços pessoais entre eles, que vão desde o simples "compadrio" à proteção de lealdades políticas. (NUNES, 2003, pp. 2627)

E essa gramática, como denominado por Nunes, é uma herança histórica que perpassa diferentes fases políticas, como observado por ele, "o clientelismo se manteve forte no decorrer de períodos democráticos, não definhou durante o período do autoritarismo, não foi extinto pela industrialização e não mostrou sinais de fraqueza no decorrer da abertura política" (NUNES, 2003, p. 33).

Assim, são perceptíveis as influências do clientelismo na política, os órgãos públicos como instituições eminentemente políticas estão suscetíveis a lidar com este padrão de troca social que modifica as estruturas organizacionais de tal forma que impacta até mesmo na execução dos procedimentos burocráticos, como afirma Nunes (2003). Sob essa ótica, o clientelismo está presente nas instituições públicas, fazendo com que a impessoalidade, a racionalidade e a busca por um profissionalismo da administração pública estejam em constante guerra com essa herança de relacionamento pessoal acima do profissional, indo de encontro aos princípios constitucionais da impessoalidade e legalidade, por exemplo.

Já em relação ao corporativismo, de acordo com Schmitter (1971 apud NUNES, 2003), se caracteriza como:

(...) um sistema de intermediação de interesses em que as unidades constitutivas estão organizadas em um número limitado de categorias singulares, compulsórias, não-competitivas, hierarquicamente ordenadas e funcionalmente diferenciadas, reconhecidas ou permitidas (senão criadas) pelo Estado e que têm a garantia de um deliberado monopólio de representação dentro de suas categorias respectivas, em troca da observância de certos controles na seleção de líderes e na articulação de demandas e apoios (SCHMITTER, 1971 apud NUNES, 2003, p. 40).

Assim sendo, alguns grupos se sobrepõem a outros, mesmo que informalmente, e são capazes de modificar comportamentos dentro da organização, impactando tanto positivamente como negativamente nas metas das instituições. Logo, este artigo se propõe, também, a identificar se os gestores percebem que há algum desses padrões de comportamentos dentro da UFRPE, ou algum outro que possa influenciar nas decisões institucionais e impactar na efetividade dos mecanismos propostos e, consequentemente, 
na eficiência do serviço prestado pela instituição. Pois, como defendido por Bergamini (2010), a avaliação de desempenho por si só não pode ser considerada como um procedimento bom ou mau, visto que se trata de mais um instrumento para conhecer melhor as pessoas comprometidas com o trabalho, sendo assim a qualidade desse instrumento está ligada principalmente as intenções e sensibilidade daqueles que a utilizam.

\section{Projeto de Lei do Senado $n^{\circ}$ 116/2017}

Em 19 de abril de 2017, a senadora Maria do Carmo Alves (DEM-SE) apresentou o Projeto de Lei do Senado (PLS) n ${ }^{\circ} 116$, que dispõe sobre a perda do cargo público por insuficiência de desempenho do servidor estável, que visa regulamentar o inciso III do parágrafo $1^{\circ}$ do art. 41 da Constituição Federal (já apresentado anteriormente), reescrito pela Emenda Constitucional $\mathrm{n}^{\mathbf{0}}$ 19, de 1998, também denominada de Reforma Administrativa, aprovada durante o governo neoliberal de Fernando Henrique Cardoso.

A proposta legislativa, em resumo, sugere que devem ser feitas avaliações de desempenho semestrais e o servidor deve ser notificado visando identificar os pontos negativos apontados na tentativa de superar as dificuldades. Os aspectos propostos para a avaliação foram denominados como "fatores avaliativos" e foram subdivididos em duas categorias "fixos" e "variáveis", os fatores avaliativos fixos, dispostos no Art. 80, são relativos a qualidade e produtividade e os fatores avaliativos variáveis (Art. $9^{\circ}$ ) abrangem doze características, são elas: (i) relacionamento profissional; (ii) foco no usuário/cidadão; (iii) inovação; (iv) capacidade de iniciativa; (v) responsabilidade; (vi) solução de problemas; (vii) tomada de decisão; (viii) aplicação do conhecimento: (ix) compartilhamento de conhecimento; (x) compromisso com objetivos institucionais; (xi) autodesenvolvimento e (xii) abertura a feedback. Na próxima seção esses fatores serão explanados de forma completa, para facilitar a comparação.

O PLS ainda prevê que "os servidores serão avaliados pelos fatores avaliativos fixos "produtividade" e "qualidade", acrescidos de cinco fatores variáveis, escolhidos de acordo com as atividades primordiais a serem realizadas no período avaliativo" (Art. 10 da PLS, p. 5) e terão pesos distintos de acordo com a escolha do avaliador.

A perda do cargo ocorrerá caso os servidores tenham menos de $30 \%$ da nota máxima em quatro avaliações seguidas ou menos de $50 \%$ em cinco das últimas dez realizadas. O projeto garante aos servidores o direito de pedir a reconsideração das notas, bem como de apresentar recurso ao órgão máximo de gestão de recursos humanos da instituição em que trabalha. A perda acontecerá, apenas, após processo administrativo, instaurado depois das primeiras avaliações negativas.

A justificativa para essa premissa é a de que a ausência da possibilidade da perda do cargo, viabilizada pela estabilidade, resulta em consequências negativas, não só por permitir que o trabalho seja realizado de forma negligente acarretando em danos diretos à instituição, como também passa a influenciar no comportamento e imagem dos demais servidores, impactando, inclusive, na percepção da sociedade que pode se sentir prejudicada pelo investimento que faz sem o devido retorno, como explicitado no trecho transcrito da Justificativa do PLS no 116/2017:

[...] Temos que ter em vista que, quando não há a perda do cargo de um agente público negligente, sérias consequências derivam dessa omissão. A sociedade se sente lesada, prejudicada, porquanto desembolsa pesados tributos para o correto funcionamento da máquina 
pública que, por sua vez, não lhe retorna o investimento em bens e serviços. Além disso, a mensagem passada aos servidores responsáveis e que prestam bem o seu papel é de que não vale a pena o esforço, pois aquele funcionário que não trabalha e que sobrecarrega os demais jamais será punido. Em verdade, o fato inegável de que a Administração Pública protege servidores irresponsáveis ajudou a criar em nosso país uma antipatia quase generalizada contra os agentes públicos em geral. Desse modo, servidores públicos dedicados, que honram cotidianamente os vencimentos que percebem e que são imprescindíveis para o cumprimento das atribuições estatais, são vistos injustamente como apropriadores da coisa pública. [...]. Deve ficar claro que não se trata aqui de punir os bons servidores, que merecem todo o apoio legal para bem cumprir seu mister. Trata-se de modificar o comportamento daqueles agentes públicos que não apresentam desempenho suficiente, especificamente daqueles que recebem ajuda da chefia imediata e do órgão de recursos humanos da sua instituição, mas, mesmo assim, optam por permanecer negligentes. (Grifo nosso) (PLS no116/2017, pp. 12-14).

Conclui-se, com isso, que a regulamentação proposta deveria ser considerada um risco apenas aos servidores que não possuem o comprometimento necessário com a coisa pública. Porém, devido à subjetividade da avaliação, há espaço para o clientelismo, corporativismo e falta de impessoalidade presentes em algumas instituições públicas, dificultando a determinação de que o processo seja livre de protecionismos e/ou de perseguições políticas ou pessoais. Por isso, esta pesquisa visa identificar se essas práticas podem influenciar na avaliação de desempenho e, consequentemente, no alcance do objetivo da proposta, para tanto irá analisar o caso à luz da percepção dos gestores da UFRPE, que em sua maioria exercem a função de avaliador de seus colegas/subordinados.

Vale salientar que não será analisada nesta pesquisa a legalidade da proposta legislativa em questão, mesmo cientes que há muitas contestações em relação à constitucionalidade da mesma, seja no que diz respeito ao conteúdo da matéria ou a competência de quem propôs o projeto. Também não entrar-se-á no mérito de estudar os ideais motivacionais e políticos de sua constituição e os impactos de sua implementação, bem como as implicações para o serviço público. Limita-se, assim, a discussão à análise da efetividade do instrumento proposto (avaliação de desempenho) como elemento para mensuração da eficiência do servidor.

\section{Fatores da avaliação proposta pelo PLS n⿳0 116/2017 versus indicadores da avaliação para progressão por mérito}

Antes de começar a explanar a análise dos dados obtidos com a pesquisa de campo, é necessária, para uma melhor compreensão dos objetos comparados, uma breve explanação entre os indicadores de desempenho das duas avaliações, mostrando o que ambas têm em comum. Portanto, no Quadro 1 expõe-se uma comparação exemplificativa entre os fatores avaliativos propostos pelo PLS (descritos nos artigos $8^{\circ}$ e $9^{\circ}$, pp. 4 e 5) e os correlatos existentes hoje na Avaliação de desempenho para progressão por mérito da UFRPE (retirados do formulário disponível no site da Pró-reitoria de Gestão de PessoasPROGEPE/UFRPE). 
Quadro 1 -Fatores Avaliativos do PLS nº116/2017 e Indicadores de desempenho do Formulário de Avaliação da PROGEPE

Fatores Avaliativos do Projeto de Lei do Senado no 116/2017

Qualidade: o avaliado realiza os trabalhos de forma adequada à finalidade a que se destinam, observando as normas e os procedimentos do órgão, e toma as providências necessárias para evitar a reincidência de erros e contribuir para a melhoria contínua.

Produtividade: o avaliado realiza os trabalhos a ele atribuídos com tempestividade, contribuindo para a obtenção dos resultados da unidade com eficiência e eficácia.

Relacionamento profissional: o avaliado cria e mantém vínculos pessoais e profissionais cooperativos e construtivos

Foco no usuário/cidadão: o avaliado atende as necessidades do cliente/cidadão com confiabilidade e presteza

Inovação: o avaliado propõe ideias aplicáveis a situações de trabalho

Capacidade de iniciativa: o avaliado busca ou propõe soluções e age em tempo oportuno, antecipando as designações da chefia e adotando comportamentos que estão além de suas atribuições diretas e que contribuem para o desempenho da unidade.

Responsabilidade: o avaliado responde por suas ações, compromete-se com suas tarefas, deveres e normas, zela por bens e informações, buscando o alcance das metas da unidade e da instituição

Solução de problemas: o avaliado propõe soluções consistentes para problemas enfrentados em situações de trabalho

Tomada de decisão: $\mathrm{O}$ avaliado adota em tempo hábil a solução mais adequada entre possíveis alternativas

Aplicação do conhecimento: o avaliado aplica oportunamente o conhecimento adquirido para a melhoria do desempenho pessoal e da equipe

Compartilhamento de conhecimento: o avaliado compartilha conhecimentos que possam ser relevantes para o desenvolvimento de pessoas ou o aperfeiçoamento de atividades
Indicadores de desempenho do Formulário de Avaliação da PROGEPE

Disciplina: Cumpre as normas e deveres, além de contribuir para a manutenção da ordem no ambiente de trabalho.

Iniciativa: Busca alternativas eficazes, visando à solução de problemas que demandam ações.

Produtividade: Contribui para o alcance das metas estabelecidas pela instituição.

Relacionamento Interpessoal: Relaciona-se cordialmente com as pessoas de forma a manter o ambiente de trabalho agradável e produtivo

Não consta indicador correlato para esse fator

Iniciativa: Busca alternativas eficazes, visando à solução de problemas que demandam ações

Liderança e Desenvolvimento de equipes: Conduz de forma equilibrada e ética a equipe de trabalho, propiciando um clima satisfatório entre seus membros e motivando seus integrantes a buscarem coletivamente $o$ alcance das metas acordadas.

Responsabilidade: Assume compromissos diante do que lhe é proposto e de suas atribuições, de maneira a responder pelos resultados.

Iniciativa: Busca alternativas eficazes, visando à solução de problemas que demandam ações.

Decisão: Consegue tomar decisões, assumindose, visando atender às prioridades e necessidades do trabalho, envolvendo todo o grupo sob a sua responsabilidade.

Conhecimento técnico: Conhece e aplica adequadamente as técnicas necessárias à realização de suas atividades

Planejamento e acompanhamento e Comunicação: Envolve-se no planejamento para favorecer o desenvolvimento dos trabalhos, acompanhando as atividades de sua equipe e sabe escutar e interagir com o outro 


\begin{tabular}{|c|c|}
\hline & $\begin{array}{l}\text { conseguindo ser claro e objetivo na transmissão } \\
\text { das informações solicitadas. }\end{array}$ \\
\hline $\begin{array}{l}\text { Compromisso com objetivos institucionais: } \\
\text { o avaliado demonstra senso de } \\
\text { responsabilidade, profissionalismo e } \\
\text { compromisso com os objetivos de sua } \\
\text { unidade. }\end{array}$ & $\begin{array}{l}\text { Comportamento ético: Age corretamente e com } \\
\text { seriedade no exercício do cargo público, } \\
\text { alinhando sua atuação aos valores da instituição }\end{array}$ \\
\hline $\begin{array}{l}\text { Autodesenvolvimento: o avaliado investe na } \\
\text { aprendizagem contínua para aprimorar seus } \\
\text { conhecimentos, habilidades, atitudes e } \\
\text { comportamentos. }\end{array}$ & $\begin{array}{l}\text { Atualização profissional: Procura atualizar-se } \\
\text { na sua área de atuação }\end{array}$ \\
\hline $\begin{array}{l}\text { Abertura a feedback: o avaliado utiliza } \\
\text { feedback recebido para aprimorar o próprio } \\
\text { desenvolvimento pessoal e profissional }\end{array}$ & $\begin{array}{l}\text { Flexibilidade: Ajusta-se positivamente a } \\
\text { situações inovadoras }\end{array}$ \\
\hline
\end{tabular}

Fonte: Elaborado pela Autora (2019)

Pode-se concluir, após esta comparação, que o formulário atual da avaliação de desempenho da UFRPE abrange em sua maioria os elementos necessários para analisar a eficiência do servidor público, de acordo com o proposto no Projeto de Lei do Senado, assim sendo, será analisada, na próxima etapa, as respostas dos gestores para o questionário aplicado.

\section{PROCEDIMENTOS METODOLÓGICOS}

Esta pesquisa do ponto de vista da sua natureza é aplicada, pois objetiva gerar conhecimentos para aplicação prática, como definida por Gil (2008, p. 27) a pesquisa aplicada "tem como característica fundamental o interesse na aplicação, utilização e consequências práticas dos conhecimentos". Quanto aos objetivos, caracteriza-se como exploratória, porque busca proporcionar maior familiaridade com o problema, com vistas a torná-lo mais explícito ou a construir hipóteses (GIL, 2007).

Quanto à abordagem do problema, esta pesquisa se enquadra como qualitativa, pois de acordo com Minayo (2008, p. 57), "a pesquisa qualitativa além de permitir desvelar processos sociais ainda pouco conhecidos referentes a grupos particulares, propicia a construção de novas abordagens, revisão e criação de novos conceitos e categorias durante a investigação", o que corrobora com o objetivo dessa pesquisa que visa analisar a efetividade do PLS por meio da percepção dos gestores, um tema ainda recente na literatura.

A trajetória metodológica da pesquisa foi iniciada com a pesquisa bibliográfica e documental, por meio das quais foi possível apresentar um breve estudo sobre a história da avaliação de desempenho e sua importância; um resumo de alguns estudos sobre a avaliação de desempenho em algumas IFES; uma explanação sobre o PLS nº 116/2017 e, por fim, a correlação entre a avaliação de desempenho da UFRPE e a avaliação proposta pelo PLS, para, com isso, demonstrar as similaridades e diferenças entre as avaliações no que diz respeito ao conteúdo e aplicabilidade, com o objetivo de evidenciar a possibilidade de comparação das avaliações propostas pelo PLS e as atuais avaliações de desempenho das IFES.

Em seguida, foi realizada a pesquisa de campo com a aplicação de questionários online (formulário Google Docs) aos gestores da UFRPE, com o intuito de identificar a percepção dos mesmos quanto à efetividade da atual avaliação de desempenho e por meio 
dela inferir a efetividade da avaliação proposta pelo PLS. Para tanto, os questionários foram subdivididos em três partes: a primeira visava identificar o perfil do gestor, e englobava as perguntas sobre o tipo de cargo de direção, o período de ingresso na IFES, o tempo que o mesmo ocupava cargo de direção e quantos servidores avaliava; a segunda parte questionava sobre a percepção dos gestores quanto à atual avaliação de desempenho da IFES, no que concerne a ser um parâmetro para análise de eficiência, os efeitos das mesmas sobre os avaliados, se os resultados refletem a real opinião dos avaliadores e os possíveis elementos que influenciam na avaliação; a terceira parte indagou sobre o PLS $\mathrm{n}^{\text {o }} 116 / 2017$ em relação a necessidade do objeto da matéria, sua efetividade em comparação com a atual avaliação e as possíveis influências para o não alcance da meta estabelecida. Todos esses itens foram abordados na seção 5, da análise dos dados.

Dentro do universo de gestores, foram selecionados como amostra os cargos de direção - CD nos níveis 2, 3 e 4, que foram identificados por meio do Banco de Dados dos Servidores do Poder Executivo Federal, disponível no Portal da Transparência ${ }^{2}$, envolvendo pró-reitores, diretores de departamento, gerente, superintendente e assessores, que somavam trinta e nove gestores no mês de junho/2017. Escolhidos por possuíram cargos administrativos de níveis estratégicos diretamente envolvidos com a gestão e execução. Após a compilação dos dados dos questionários, foi feita a análise dos resultados obtidos, comparados com as demais pesquisas semelhantes e realizadas as inferências possíveis.

\section{ANÁLISE E DISCUSSÃO DOS DADOS}

Nesta seção, será descrito e discutido os dados obtidos dos questionários aplicados a trinta e nove gestores, dentre eles, pró-reitores, gerente, superintendente, diretores gerais, diretores de departamento, diretores de núcleo e assessores. Destes trinta e nove gestores que foram consultados em junho/2017, obteve-se respostas de dezenove chefes (aproximadamente $50 \%$ da população selecionada). Desse modo, primeiro será apresentado o perfil dos gestores que responderam ao questionário para depois ser realizada a análise das suas opiniões e percepções quanto ao tema da pesquisa.

Quanto ao tipo de Cargo de Direção ocupado, que são divididos em Cargos de Direção 2, 3 e 4, a maior parte dos respondentes possui cargo de direção CD4 (68,4\%), que são em sua maioria os diretores de departamento e de núcleo e os assessores, que estão, quase sempre, mais envolvidos com a execução, e os cargos de níveis CD2 e CD3 ficou dividido em 15,8\% cada, que são os pró-reitores (CD2) e gerente, superintendente, diretores gerais, assessor especial (CD3), que estão mais envolvidos com a gestão.

Em relação ao período de ingresso na UFRPE, 63,2\% do total dos entrevistados ingressaram depois de 2004, sendo assim, entraram na IFES quando já existia tanto o Princípio da eficiência quanto o Plano de Cargo e Carreiras e, consequentemente, a avaliação de desempenho, 15,8\% ingressaram de 1988 a 1998, ou seja, quando não havia nenhum dos dois, apenas a Constituição Federal e desta forma realizaram concurso público, e $21 \%$ entraram antes de 1988, sendo anteriores até mesmo ao concurso público.

Os chefes exercem cargo de direção em sua maioria $(57,9 \%)$ há mais de 4 anos, $26,3 \%$ de 2 a 4 anos e 15,8\% menos de 2 anos, assim sendo, observa-se que já possuem uma experiência considerável como gestores na Instituição. $73,7 \%$ destes gestores são

\footnotetext{
${ }^{2}$ Disponível em: http://www.portaltransparencia.gov.br/downloads/servidores.asp\#getC.
} 
responsáveis por avaliar mais de 6 pessoas na avaliação de desempenho para progressão, ficando 26,3\% com a responsabilidade de avaliar de 1 a 6 servidores apenas.

Traçado o perfil dos gestores que participaram da pesquisa, pode-se agora verificar a percepção dos mesmos em relação à avaliação de desempenho para progressão por mérito, no que se refere à análise tanto como instrumento para medir a eficiência do servidor, como também, a confiabilidade dos seus dados, dentre outros aspectos abordados no questionário, em seguida será feita uma análise da opinião dos gestores, especificamente, em relação ao PLS.

Como se pode observar no Gráfico 1, 31,6\% dos chefes acreditam que a avaliação para progressão pode ser utilizada como parâmetro para a análise de eficiência do servidor, e a maioria $(68,4 \%)$ acredita que pode ser utilizada apenas para alguns servidores $(42,1 \%)$ e/ou que não pode ser utilizada como parâmetro para a análise $(26,3 \%)$. Como apresentado anteriormente, os indicadores analisados na atual avaliação da IFES se assemelham, em sua maioria, aos fatores avaliativos propostos pelo PLS, ou seja, em sua essência a avaliação está de acordo com os elementos apresentados pelo projeto como necessários para analisar a eficiência do servidor, excetuando-se pelo quesito "foco no usuário/cidadão". Portanto, pode-se inferir que na percepção da maioria dos gestores, os fatores que compõem a avaliação não são úteis na análise da eficiência/produtividade para todos os servidores, o que também foi identificado na UFPE, que tem a avaliação semelhante à da IFES aqui analisada, por meio da pesquisa de Azevedo (2015, pp. 69-70), que obteve na sua análise de resultados as opiniões de que "a avaliação de desempenho funcional é superficial, geral por não conseguir avaliar se o profissional é realmente bom e se contribui para a universidade" e "a avaliação de desempenho funcional não valoriza o cumprimento de metas e resultados".

Gráfico 1. A atual avaliação de desempenho como instrumento de análise da eficiência do servidor

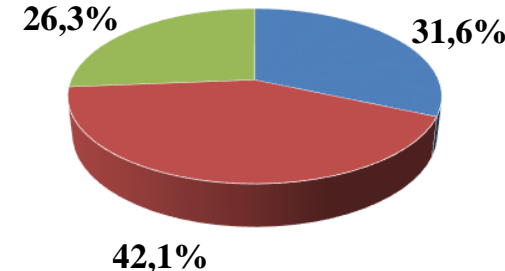

$42,1 \%$

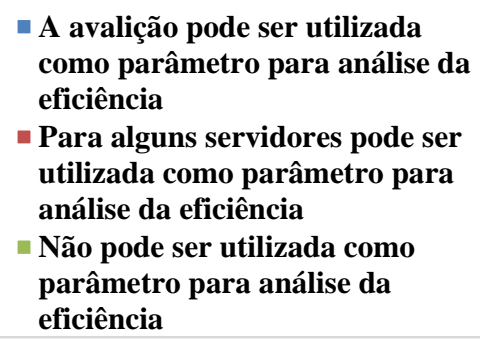

Fonte: Elaborado pela Autora (2019)

Juntando-se a essa discussão os dados do Gráfico 2, em que se observa a percepção das chefias em relação ao impacto da avaliação de desempenho após o feedback, pode-se concluir que muitos servidores não são influenciados pelo resultado de sua avaliação, considerando que $68,4 \%$ percebem impactos nas atividades de apenas alguns servidores, $21,1 \%$ não percebem impacto nenhum, enquanto $10,5 \%$ percebem impactos após o feedback, corroborando com o observado na pesquisa de Azevedo (2015, p. 149), que identificou que a "avaliação de desempenho promove a reflexão para alguns sujeitos, para outros, a avaliação não estimula a autocrítica, sendo esta decorrente da sua própria consciência”. 
Gráfico 2. Impactos da avaliação de desempenho em relação às atividades dos servidores

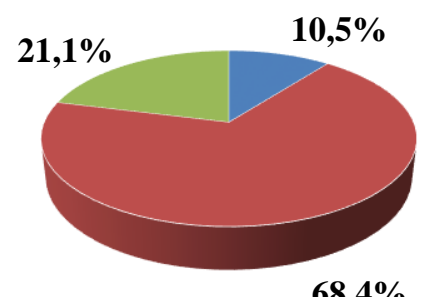

- Há impactos após o feedback

- Em alguns casos há impactos após o feedback, depende do servidor

- Não há impactos após o feedback

— Não observa

Fonte: Elaborado pela Autora (2019)

O que abre um leque de possíveis motivos, dentre eles, sugere-se: (i) o desinteresse de alguns servidores pela melhoria contínua, servidores que acreditam que já contribuem o suficiente e não querem melhorar suas ações, ou simplesmente que não estão dispostos a mudar suas atividades para colaborar com a instituição, fazendo o mínimo necessário confiando na estabilidade do cargo; (ii) a blindagem política causada pelo clientelismo que faz com que alguns servidores não estejam preocupados com suas "notas", considerando que não serão afetados por resultados negativos, clientelismo que foi interpretado por Ferreira (2014), no contexto da Administração Pública, como sendo: "a utilização da máquina pública pelo titular do poder, visando satisfazer interesses pessoais através da concessão de benefícios a terceiros que, em razão deles, ficam politicamente vinculados com aquele que lhe prestou o favor, devendo, portanto, retribuir o que lhe foi concedido"; (iii) a sensação de iniquidade e/ou de injustiça em decorrência desse clientelismo, ou de outro fator qualquer, que faça com que o servidor perceba que há uma divergência entre as suas contribuições e o retorno das mesmas por meio das avaliações, seja de forma individual ou em comparação com seus colegas, conforme pontuado por Liberato (2015, p. 55) quando indica que "a sensação de justiça é essencial para criar na pessoa que está sendo avaliada, certas atitudes positivas com relação à avaliação, devendo ela existir em todas as ações relacionadas ao desempenho da pessoa."; ou até mesmo pelo fato apontando na análise do Gráfico 1 que, (iv) os servidores, assim como alguns gestores, não consideram o instrumento como efetivo para medir a eficiência do servidor, não sendo dessa maneira útil como elemento para uma mudança comportamental, como evidenciado por Azevedo (2015, p. 68), quando menciona que "a avaliação de desempenho funcional é feita por obrigação, figurando como um procedimento formal para progressão na carreira".

No que diz respeito à confiabilidade dos dados da avaliação de desempenho para progressão e a percepção dos gestores em relação à eficiência dos servidores, verifica-se por meio dos Gráficos 3, 4 e 5 que apesar de 42,1\% dos avaliadores considerarem que há em seu setor servidor que não atende plenamente os requisitos necessários para exercer as atividades que lhe são delegadas, contra $36,8 \%$ que acreditam que não há, a maioria dos gestores $(68,4 \%$, somando os que consideram que a maioria delas reflete, $57,9 \%$, e a maioria delas não reflete a realidade, 10,5\%) assume que não avalia todos os seus subordinados de acordo com sua real opinião e apenas $26,3 \%$ afirmam que avaliam todos de acordo com sua real percepção, bem como acreditam que 89,5\% dos próprios servidores e seus colegas de equipe não respondem o formulário totalmente de acordo com a realidade percebida, mostrando com isso que na grande maioria dos casos não há impessoalidade por parte dos avaliadores e dos colegas na avaliação de desempenho. Falta de impessoalidade essa, também evidenciada por Costa (2018) na sua pesquisa realizada 
no Instituto Federal do Espírito Santo (IFES- campus de Alegre), em que encontrou como resultado que a relação entre avaliador e avaliado influencia na avaliação, de acordo com a percepção dos servidores, como destacou:

Chefias (64\%) e servidores administrativos em Educação (90\%) consideram que as relações interpessoais influenciam na avaliação de desempenho pela chefia imediata. Vê-se pelo resultado que os avaliados acreditam que uma proximidade ou um distanciamento dos colegas e da chefia imediata que conduz a avaliação poderá influenciar o resultado da avaliação de desempenho. No entanto, ao verificar-se que os avaliadores também concordam com esta opinião, conclui-se que este processo pode comprometer a qualidade final da avaliação (COSTA, 2018, p. 47).

Gráfico 3. A percepção dos gestores em relação a servidores com insuficiência de desempenho

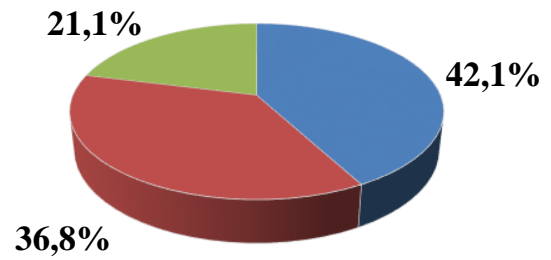
— Há servidor com insuficiência de desempenho
n Não há servidor com insuficiência de desempenho
- Prefere não responder

Fonte: Elaborado pela Autora (2019)

Gráfico 4. Reflexão sobre as avaliações de desempenho realizadas pelos gestores em relação a real opinião sobre os servidores

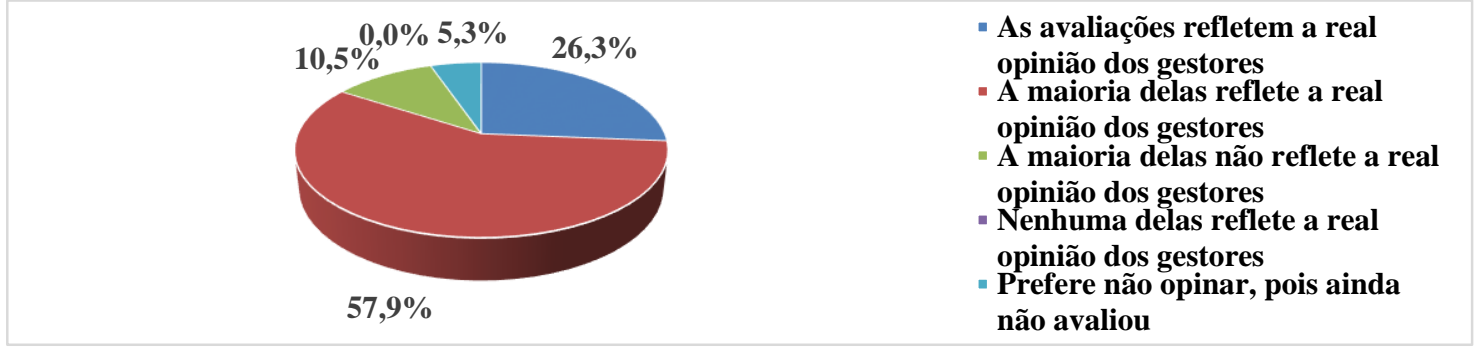

Fonte: Elaborado pela Autora (2019)

Gráfico 5. A percepção dos gestores em relação à fidedignidade da avaliação realizada pelos próprios servidores e seus colegas

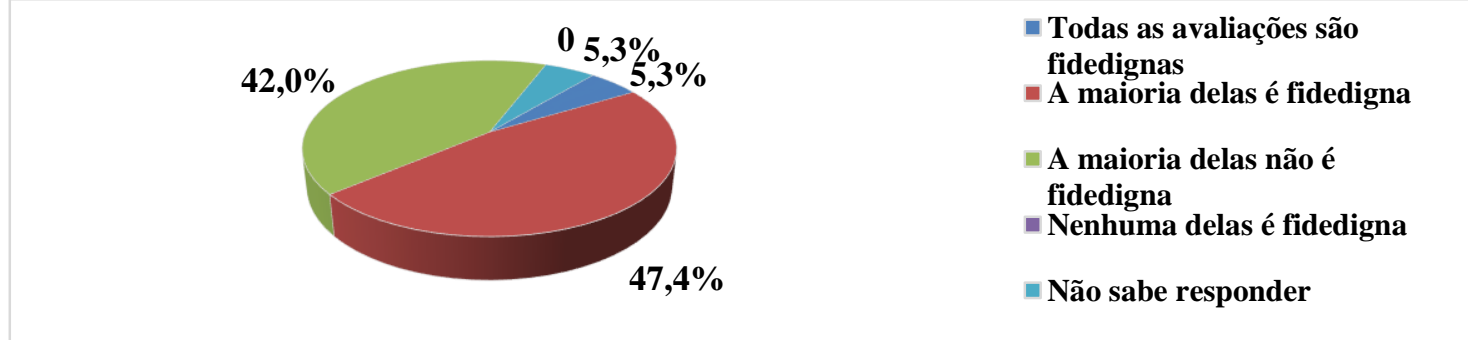

Fonte: Elaborado pela Autora (2019)

Como sugerido anteriormente, essa falta de impessoalidade pode trazer um sentimento de injustiça pelos avaliados, decorrendo em insatisfação e falta de credibilidade no instrumento de avaliação, como exposto por Costa (2018, p. 46), que 
verificou que a maioria dos servidores considera que "ocorrem injustiças na avaliação de desempenho dos servidores. O resultado obtido nesta questão reflete a insatisfação que chefias e servidores têm com a avaliação de desempenho, fato este que compromete a funcionalidade do instrumento de gestão".

Os principais motivos para a falta de fidedignidade estão explicitados no Gráfico 6, destacando-se o fato de que os gestores não querem causar prejuízos financeiros aos subordinados $(46,2 \%)$, função primordial da avaliação de desempenho para progressão de acordo com o senso comum, como destacado na pesquisa realizada por Martins (2018, p. 91) no Instituto Federal de Educação, Ciência e Tecnologia do Ceará (IFCE), em que constatou que os servidores em sua maioria $(57,8 \%)$ "acreditam que a razão de ser da avaliação é a retribuição pecuniária". Bem como não querem criar indisposição no setor, pois uma avaliação desfavorável de um servidor pode causar tanto efeito negativo no mesmo, como também, resultar em uma comoção dos colegas de trabalho, causando assim uma insatisfação geral do setor e consequências desastrosas para o andamento do trabalho, devido ao corporativismo institucional, o que afeta diretamente a qualidade do serviço. Como abordado por Nunes (2003), o corporativismo na teoria surge de uma tentativa prática de organizar e racionalizar os grupos informais, nas palavras dele "No Brasil, no Peru e no México, o corporativismo foi utilizado como uma tentativa de controlar e organizar as classes inferiores através de sua incorporação ao sistema" (NUNES, 2003, pp. 39-40).

Gráfico 6. Motivações dos chefes para as avaliações divergentes da realidade percebida

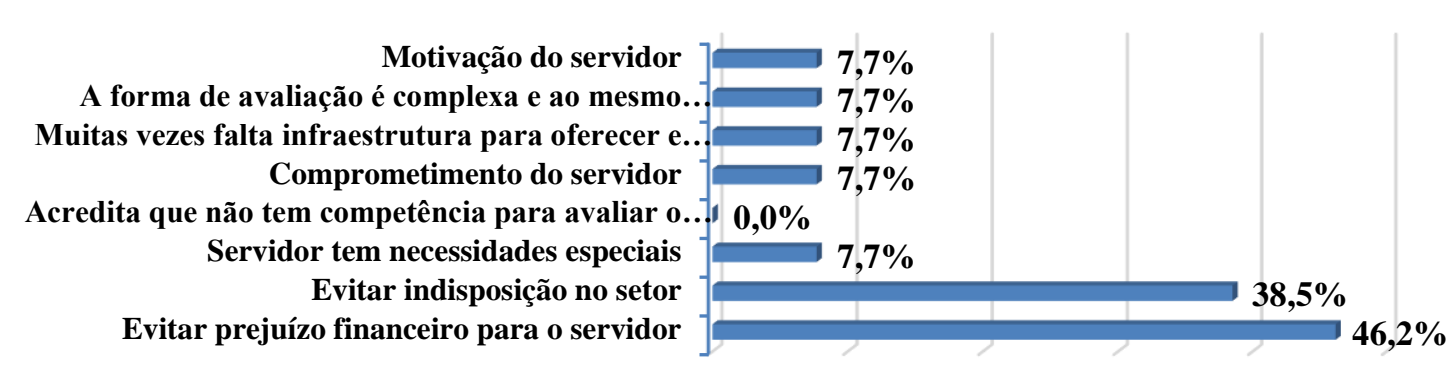

Fonte: Elaborado pela Autora (2019)

O corporativismo está presente em muitas instituições públicas, e no que diz respeito a avaliação de desempenho de servidores em instituições de ensino é bastante comum, como constatado também por Pita (2018) em sua pesquisa na Universidade Estadual da Paraíba (UEPB), em que verificou que há um forte corporativismo no momento das avaliações de desempenho, e concluiu que "com finalidade de obter um bom resultado e adquirir a estabilidade ou progressão por tempo de serviço, o que se distancia de um julgamento efetivo do desempenho do servidor, o processo avaliativo termina sendo utilizado de maneira burocrática, sem que o PAD traga o retorno desejado" (PITA, 2018, p. 146).

Também é válido destacar que uma causa para a avaliação ser divergente da realidade percebida, apesar de não apontada na presente pesquisa, porém verificada em algumas pesquisas, é o fato de que os avaliados também poderão ser avaliadores em outro momento, tornando assim a avaliação uma mera "troca de favores", distanciando-a de sua real finalidade. Como identificado por Pita (2018), pelas falas dos servidores entrevistados na sua pesquisa: 
As falas dos sujeitos entrevistados denotam a falta de imparcialidade relativa ao resultado da avaliação, pois é comum se avaliarem com notas mais altas do que realmente remete o seu desempenho, bem como os pares também avaliarem com notas mais altas, pois serão avaliados por quem eles estão avaliando, conforme fala dos sujeitos: [...] se você olhar o sistema como um todo, dois servidores se trabalhar no mesmo conjunto pode ocorrer de um botar 10 no outro e o outro 10 nele [...] (GP-2, informação verbal). [...] eu sou seu colega eu vou lhe avaliar bem porque eu sei que você vai ser meu colega e você pode me avaliar mal na próxima avaliação [...] (GP-6, informação verbal). [...] os pares ficam com medo de dar uma nota mais baixa, porque o outro vai ficar com raiva; a chefia pode ter uma ligação com você e acaba fazendo uma nota boa, mesmo naqueles pontos tendo uma deficiência, por exemplo... [...] se você tem uma afinidade muito grande com a chefia, a chefia fica meio que envergonhada em colocar um ponto negativo lá na sua avaliação que tenha proximidade [...] (TA-4, informação verbal) (PITA, 2018, p. 111).

Além desses motivos, os gestores também apontaram outras causas para as avaliações divergentes da realidade percebida, conforme Gráfico 6, como a motivação do servidor, o comprometimento, a falta de infraestrutura para oferecer e, consequentemente, para cobrar, servidor tem necessidades especiais, a forma de avaliação complexa e ao mesmo tempo que coloca o avaliador em situação constrangedora. Com isso, conclui-se que há diversos motivos para que os gestores não realizem a avaliação de desempenho com imparcialidade e fidedignidade.

Desse modo, passa-se para o segundo momento da análise, que se propõe verificar a opinião dos entrevistados em relação a necessidade de um programa de desempenho, conforme proposto no PLS (com possível perda do cargo público), bem como comparar a efetividade da avaliação deste Projeto, considerando a credibilidade das respostas da avaliação de desempenho para progressão já existente.

Considerando que o Projeto propõe avaliar a eficiência do servidor, para fins de melhoria (e/ou readequação) do serviço, com possível perda do cargo público, foi questionado aos gestores se os mesmos achavam necessário um tipo de instrumento com esta finalidade, e 52,6\% afirmaram que é necessário um instrumento para medir a eficiência do servidor, porém sem a possibilidade da perda do cargo, enquanto 47,4\% consideraram que era necessária a possível perda do cargo para alcançar a efetividade da proposta. Com isso, observa-se que a maioria dos gestores apesar de concordarem com a necessidade de um instrumento para medir a eficiência dos servidores (considerando que nenhum gestor respondeu que não era necessário) não veem como solução para atingir o objetivo a "ameaça" da perda do cargo. O que se pode inferir, de certa forma, ao corporativismo enraizado na nossa cultura, ou às injustiças e falta de fidedignidade evidenciadas nas avaliações já existentes, como exposto na análise anterior.

No que concerne ao PLS especificamente, 57,9\% dos entrevistados já conheciam o Projeto, enquanto 42,1\% não conheciam. E esse percentual se repetiu para o julgamento da importância do PLS (após uma breve explanação do mesmo no questionário), 57,9\% julgaram-no importante para alcançar a eficiência no serviço público, contra $42,1 \%$ que não são a favor desta metodologia. $\mathrm{O}$ que de certa forma apresenta uma pequena contradição com os números expostos acima, em que a maioria de 52,6\% considerava que era necessário um instrumento, mas sem a perda do cargo, como proposto no Projeto. $\mathrm{O}$ 
que se supõe é que quando apresentado em formato de Projeto com um teor formal e racional, passa a ter mais credibilidade e apoio.

Para concluir esta análise avaliar-se-á a percepção dos gestores em relação à comparação entre a efetividade percebida na atual avaliação e a projeção para a avaliação proposta pelo PLS. Como observa-se nos Gráficos 7 e 8, 57,9\% dos gestores não acreditam que haverá efetividade na avaliação de desempenho proposta e apenas 10,5\% acreditam que haverá efetividade, enquanto $31,6 \%$ não soube responder.

$\mathrm{E}$ as razões para esta descrença na efetividade da avaliação estão listadas no Gráfico 8, destacando-se, o receio de retaliação por parte dos servidores e colegas e a proteção política com $72,7 \%$ cada, a falta de interesse por parte dos envolvidos $(63,6 \%)$, a subjetividade na avaliação por parte do avaliador $(54,5 \%)$, a falta de credibilidade no avanço processual $(45,5 \%)$ e a falta de aptidão dos avaliadores com $45,5 \%$.

Gráfico 7. Efetividade da avaliação proposta pelo PLS versus Efetividade da Avaliação de desempenho

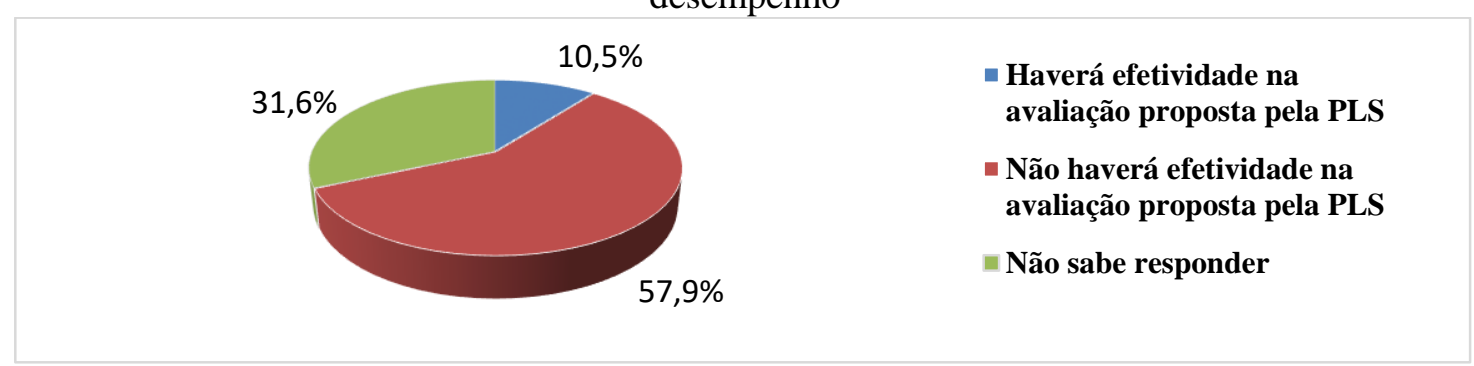

Fonte: Elaborado pela Autora (2019)

Gráfico 8. Razões determinantes para a ausência de efetividade da avaliação proposta pelo PLS

Ninguém irá avaliar mal para não ser mal avaliado Falta de aptidão dos avaliadores Proteção política de alguns servidores Receio de retaliação por parte do servidor e dos Falta de interesse por parte dos envolvidos Falta de credibilidade no avanço processual Subjetividade por parte do avaliador

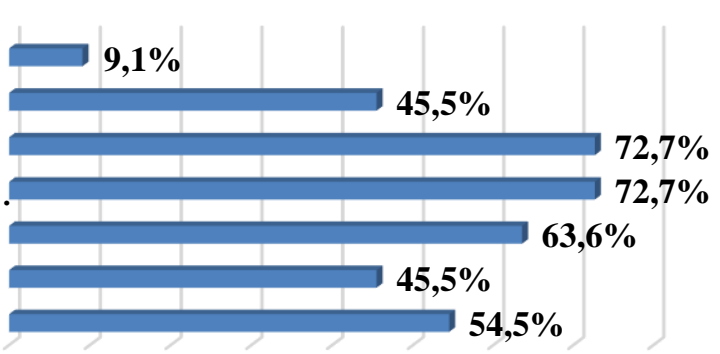

Fonte: Elaborado pela Autora (2019)

Por meio desta análise, verifica-se que os gestores percebem a necessidade de uma avaliação que analise a eficiência dos servidores, porém não acreditam que a avaliação será livre de subjetividade por parte dos avaliadores, devido, principalmente, à proteção política por parte de alguns servidores e ao receio da retaliação dos colegas, causado pelo corporativismo instaurado na instituição, já vivenciadas no processo de avaliação de desempenho existente.

\section{CONSIDERAÇÕES FINAIS}

Pode-se concluir que a avaliação de desempenho para progressão por mérito não é percebida pela maioria dos gestores da UFRPE participantes da pesquisa como um instrumento efetivo para a análise da eficiência dos servidores, corroborando com outras pesquisas apresentadas em diferentes instituições de ensino. Em parte, pode-se relacionar 
ao conteúdo da ferramenta, que não contempla indicadores de resultados reais, por exemplo, considerando que dentre os aspectos abordados não avalia as metas traçadas e alcançadas, e/ou ao método de aplicação, que por ser subjetivo possibilita a impessoalidade nas avaliações.

Como apontado na pesquisa, os gestores alegam que muitas vezes a proteção política por parte de alguns servidores não permite aos mesmos uma avaliação condizente com a realidade, bem como a preocupação com uma possível retaliação por parte do servidor e dos colegas, atitudes essas decorrentes do clientelismo e corporativismo ainda presente nas instituições públicas. Outro ponto importante, levantado na pesquisa de Pita (2018), que carrega a atividade de subjetividade na avaliação é o relacionamento entre avaliado e avaliador, em que a amizade pode interferir no julgamento, bem como a rotatividade entre os envolvidos na avaliação.

Por analogia, considerando a essência do instrumento (como comparado na seção 3) e a forma de aplicação, semelhante à proposta pelo Projeto de Lei do Senado, a maioria dos gestores não acredita que a avaliação decorrente do PLS irá ser efetiva. Ou seja, caso se perpetue esse formato e método, caso sancionada, a lei será apenas mais um instrumento pro forma, realizado por obrigação sem alcançar o objetivo principal da melhoria do serviço público por meio da incorporação real do princípio da eficiência, devido, principalmente, às práticas clientelistas e corporativistas que ainda estão fortes nas instituições públicas.

Porém, mesmo com essa perccepção, todos os gestores consideram que é necessária a inclusão de um instrumento capaz de inferir a eficiência dos servidores, apesar de uma pequena maioria concordar que não deve o servidor perder o cargo por conta de possíveis resultados negativos nessa avaliação. Logo, é necessário, para a melhoria contínua do serviço público, a implantação de um método que sirva efetivamente como elemento transformador nas instituições, sendo útil tanto para auxiliar no alcance da eficiência, quanto para a gestão das pessoas, causando impacto nos avaliadores, mas principalmente nos avaliados.

Então, não se faz necessária apenas a criação de métodos legais para essa melhoria, mas sim a quebra de paradigmas com o intuito de modificar essa herança de troca de favores, protecionismo e corporativismo, em busca de profissionalismo com a verdadeira mudança da cultura organizacional. Criando, quem sabe, uma forma real para alcançar o objetivo de trazer a eficiência para o serviço público, livrando as práticas clientelistas e corporativistas, inter-relacionando, com outras formas de gestão, como por exemplo, mecanismos de benefícios mútuos ou estudos motivacionais, com a ideia de que por meio da satisfação pessoal e envolvimento com o verdadeiro sentido da administração pública se possa alcançar a meta de prestar serviços de qualidade trazendo a satisfação coletiva, evitando a visão apenas punitiva, baseada no medo. Nesse sentido de atingir uma efetividade da avaliação de desempenho, Costa (2018) defende que:

Para uma avaliação de desempenho se tornar efetiva e bem sucedida, a organização deve ser composta de elementos que não dependam só desse instrumento, os gestores devem promover as adaptações necessárias que demandam um processo sistêmico. A avaliação de desempenho tem um papel muito importante na vida organizacional e profissional, mas ainda se encontra com muita dificuldade em sua aplicação devido à falta de compreensão de seu real valor e para as decisões gerenciais ou apenas para a formalidade no cumprimento da lei (COSTA, 2018, p. 18). 
Salienta-se que apesar do objetivo da pesquisa ter sido alcançado, há limitações no estudo para uma conclusão mais abrangente, considerando três pontos: primeiro no que concerne ao público respondente que foi limitado aos gestores da UFRPE, necessitando assim de uma amostra mais representativa; segundo porque a pesquisa é baseada na percepção dos gestores, tornando-se assim subjetiva; terceiro, devido à comparação entre as alternativas das avaliações ter sido realizada por meio da interpretação pessoal da presente autora. Mas, mesmo com essas ressalvas, pretende-se ainda com esta pesquisa contribuir no que diz respeito a levantar o interesse pela discussão da efetividade do projeto aqui em questão, que é considerado importante para a medida de eficiência no serviço público, mas que deve ter estudos prévios e mudanças comportamentais nas instituições para ser implementado de forma efetiva.

\section{REFERÊNCIAS}

AZEVEDO, R. B. de. A política de avaliação de desempenho da UFPE: a perspectiva dos servidores técnico-administrativos em educação. 2015. 187 f. Dissertação (Mestrado em Gestão Pública para o Desenvolvimento do Nordeste) - Universidade Federal de Pernambuco, Recife. Disponível em: https://repositorio.ufpe.br/handle/123456789/13857. Acesso em: 30 maio 2019.

BERGAMINI, C.W.; BERALDO, D. G. R. Avaliação de desempenho humano na empresa. 4. ed. São Paulo: Atlas, 2010.

BERGUE, S. T. Comportamento Organizacional. Florianópolis: Departamento de Ciências da Administração/UFSC; Brasília: CAPES: UAB, 2010. 114p.: il.

BRASIL. Senado Federal. Projeto de Lei do Senado n. 116, de 2017.Regulamenta o art. $41, \S 1^{\circ}$, III, da Constituição Federal, para dispor sobre a perda do cargo público por insuficiência de desempenho do servidor público estável. Brasília, DF, 2017.Disponível em:https://legis.senado.leg.br/sdleg-etter/documento?dm=5237175\&disposition=inline. Acesso: 03 jun. 2017.

COSTA, R. S. da. Avaliação de desempenho dos servidores administrativos: um instrumento de gestão? 2018. 81 f. Dissertação (Mestrado em Gestão Pública) Universidade Federal do Espírito Santo, Alegre - ES. Disponível em: http://repositorio.ufes.br/jspui/handle/10/10630. Acesso em: 30 maio 2019.

FERREIRA, M. C. O Clientelismo e os Cargos Comissionados: Impacto na Eficiência da Administração Pública. São Paulo: 2014. Disponível em: http://www.ambitojuridico.com.br/site/?n_link=revista_artigos_leitura\& artigo_id=14137. Acesso em 23 jun. 17.

GIL, A. C. Como elaborar projetos de pesquisa. 4. ed. São Paulo: Atlas, 2007.

GIL, A. C. Métodos e técnicas de pesquisa social. 6. ed. São Paulo: Atlas, 2008.

LIBERATO, M. S. De passiva a proativa: uma abordagem da atitude frente à avaliação de desempenho na Administração Pública - o caso do IFES campus Linhares. 2015. 150 f. Dissertação (Pós-Graduação em Gestão Pública) Universidade Federal do Espírito Santo, Vitória. Disponível em: http://repositorio.ufes.br/bitstream/ 10/2519/1/tese_9038_Disserta\%C3\%A7\%C3\%A3o\%20Final\%20-

\%20Midra\%20Sian\%20 Liberato20150805-125607.pdf. Acesso em: 10 jul. 2019. 
LUCENA, M. D. da S. Visão crítica da avaliação de desempenho. In: Avaliação de desempenho. São Paulo: Atlas, 1995. p. 35-51.

MARTINS, P. U. Avaliação de desempenho dos servidores técnico-administrativos de um Instituto Federal de educação na perspectiva de técnicos e gestores de pessoas. 2018. 132 f. Dissertação (Mestrado em Políticas Públicas e Gestão da Educação Superior) - Universidade Federal do Ceará, Fortaleza. Disponível em: http://www.repositorio.ufc.br/handle/riufc/38347. Acesso em: 5 jun. 2019.

MEIRELLES, H. L. Direito administrativo Brasileiro. 28. ed. atual. São Paulo: Malheiros, 2003.

MINAYO, M. C. S. O desafio do conhecimento: pesquisa qualitativa em saúde. São Paulo: Hucitec, 2008.

NUNES, E. A Gramática Política do Brasil. Clientelismo e Insulamento Burocrático. 3. ed. Rio de Janeiro: Jorge Zahar, 2003.

PITA, U. S. Processo de avaliação de desempenho dos servidores técnicoadministrativo da Universidade Estadual da Paraíba. 2018. 166 f. Dissertação (Mestrado em Gestão nas Organizações Aprendentes) - Universidade Federal da Paraíba, João Pessoa. Disponível em: https://repositorio.ufpb.br/jspui/handle/123456789/12573. Acesso em: 5 jun. 2019.

PROGEPE. Formulário para Avaliação de Desempenho. Disponível em: http://sugep.ufrpe.br/sites/ww2.sugep.ufrpe.br/files//Formul\%C3\%A1rio\%20SEM\%20F UN\%C3\%87\%C3\%830\%20novo.pdf. Acesso em: 10 jun. 2017.

Retratos da Sociedade Brasileira: Serviços públicos, tributação e gasto do governo, 2016. Número 33. Disponível em: http://www.portaldaindustria.com.br/estatisticas/rsb33-servicos-publicos-tributacao-e-gasto-do-governo/. Acesso em 20 jun. 2017. 